\title{
World of warcraft como prática de lazer: sociabilidade e conflito "em jogo" no ciberespaço.
}

Fernando Renato Cavichiolli* Leoncio José de Almeida Reis**

\begin{abstract}
Resumo: World of Warcraft é um jogo digital bastante conhecido e jogado no mundo todo. No mundo virtual do jogo, milhares de pessoas conectadas à internet se reúnem para interagir, se relacionar e compartilhar a experiência de jogar. Este texto é uma síntese dos principais achados de pesquisa etnográfica que abordou o jogocomo prática de lazer e a partir da perspectiva dos jogadores. Dentre os principais temas discutidos, estão questões referentes aperformance, competição, sociabilidade e violência.
\end{abstract}

Palavras chave: Jogos eletrônicos digitais. Lazer. Sociabilidade. Violência.

\section{INTRODUÇÃo}

Este texto é uma síntese dos principais achados de pesquisa envolvendo jogadores do jogo de computador World of Warcraft. Por ser o mais popular e conhecido de seu gênero, o jogo foi utilizado como campo de estudo para o desenvolvimento de pesquisa de doutorado em Educação Física (REIS, 2013) cuja problemática central foi interpretar, no contexto da comunidade brasileira de jogadores, como diferentes experiências de jogar eram construídas a partir do entrelaçamento entre o jogar e o interagir socialmente.

À primeira vista, pode parecer paradoxal discutir em um periódico cujo título remete à ideia de deslocamento, de mudança

\footnotetext{
"Curso de Educação Física, Universidade Federal do Paraná, Curitiba, PR, Brasil. E-mail: cavicca@hotmail.com.

"Curso de Educação Física, Universidade Federal do Paraná (Litoral), Matinhos, PR, Brasil. E-mail: leojar_edf@yahoo.com.br.
} 
de lugar, de ação no espaço, enfim, de "Movimento", um tipo de prática que exige pouco ou quase nenhum movimento corporal para os padrões dos jogos motores tradicionais: a prática dos jogos digitais.

Já se sabe, contudo, que discussões e experiências pedagógicas no âmbito da Educação Física têm estreitado relações com as práticas dos jogos digitais - e isso há mais de uma década, como prenunciava o trabalho de Feres Neto (2001) sobre a virtualização do esporte.

A incorporação do movimento corporal - antes ausente ou discreto demais - nas práticas dos jogos digitais agora aparece com destaque nas notícias, propagandas e comerciais do ramo. Consoles de última geração trazem mecanismos que captam movimentos corporais e oferecem jogos que substituem o apertar de botões pelo balançar dos membros, pelo saltitar, pelo equilibrar-se, pelo dançar, etc. Em suas utilizações mais ousadas, de eletroeletrônico destinado ao lazer, à diversão e ao entretenimento, viraram aparelho de condicionamento físico em academias de ginástica e instrumento para tratamentos terapêuticos em clínicas fisioterápicas. Pesquisas acadêmicas como em Peng, Crouse e Lin (2013) inclusive já tentam mapear o atual estado da arte de pesquisas envolvendo a eficiência dos recém-batizados exergames(EXG) ou active videogame (AVG).

Adentrando a fronteira da escola, o tema dos jogos digitais também parece ter encontrado espaço em meio à discussão das práticas pedagógicas da Educação Física, sendo considerados "relevante mecanismo de socialização, diversão e aprendizagem" (ARAUJO et al., 2011, p.607). Não poderia ser diferente: uma prática escolar que se pretendente manter aberta e atualizada às experiências que os alunos constroem fora dela não poderia deixar de resgatar e abordar práticas corriqueiras e significativas quepermeiamo cotidiano e o imaginário desses alunos - como é o caso dos próprios jogos digitais. Já existem relatos de experiências pedagógicas que, percebendo a sedução dos alunos pelos jogos e outras mídias da atualidade, buscam somar e atualizar essas experiências dentro do contexto das práticas educativas

Movimento, Porto Alegre, v. 20, n. 3, p. 1083-1109, jul./set. de 2014. 
curriculares - é o que propõe trabalhos como o de Costa (2006) ou então utilizar os próprios jogos digitais como estimuladores de aprendizagens motoras - como em Baracho et al. (2012).

A relação entre a prática de jogos digitais e o universo da cultura corporal de movimento não se restringe às relações mais evidentes já citadas. Pereira (2009), por exemplo, defende que a construção de experiências dos sujeitos nos ambientes virtuais - dos jogos digitais ou de plataformas de sociabilidade como o Second Life - não deixa de estar atrelada a noções de corpo e de movimento, portanto, articulado a objetos clássicos da Educação Física. Virtuais ou não, ambos (corpo e movimento) seriam mediadores da nossa relação com o mundo. A cultura corporal de movimento assim entendida não deixaria de estar presente no e através do ciberespaço, lugar de "vivência/projeção/representação corporal não-encarnada", como explora outro trabalho nessa linha, de Cruz Júnior e Silva (2010).

Por fim, jogos digitais se aproximam da Educação Física enquanto são observados como manifestações culturais de lazer, pois é de conhecimento que os estudos e pesquisas desenvolvidos no campo do lazer no Brasil estão historicamente vinculados à Educação Física, sendo essa a área que abriga mais pesquisadores e grupos de pesquisa envolvidos com o tema. Foi dessa área que parti para discutir uma prática em especial: o jogar World of Warcraft.

\section{SOBRE O WORLD OF WARCRAFT}

Tendo estabelecido um novo paradigma no mercado dos jogos digitais e se tornado referência para jogos do gênero, World of Warcraft - ou simplesmente WoW- é o mais conhecido e referenciado, como também o mais jogado entre os MMORPGs pagos (BAINBRIDGE, 2010). Nos MMORPGs (Massive Multiplayer Online Role Playing Game) os jogadores (milhares e até mesmo milhões) compartilham continuamente a experiência do jogar num mesmo mundo virtual. São jogos criados justamente visando proporcionar maior interação social entre os jogadores,

Movimento, Porto Alegre, v. 20, n. 3, p. 1083-1109, jul./set. de 2014. 
possibilitando inclusive que estabeleçam algum tipo de relação social mais ou menos intensa e duradoura.

No universo virtual lúdico do jogo, milhares de jogadores, de diversas idades, de diferentes contextos socioculturais e de vários lugares do globo se reúnem para jogar, competir, interagir e socializar (NARDI, 2010). Está disponível em mais de nove línguas, incluindo o Português. No início de 2013, contava com mais de 10 milhões de assinantes que pagavam mensalmente para ter acesso ao jogo, afirmando-se como uma prática de lazer bastante acessada no meio. Já é considerado, sem dúvida, um marco na história dos games.

O jogo ocorre em um ambiente tridimensional criado sinteticamente por processamento gráfico que simula características físicas (gravidade, espacialidade, etc.), visuais e sonoras baseadas no nosso mundo (Figura 1). Nele, os jogadores podem, através de seus personagens (avatares), moverem-se pelo espaço, interagirem com seus elementos e se relacionarem com outros jogadores conectados. É nesse espaço virtual que o jogar propriamente dito ocorre. Ou seja, é ali onde os jogadores podem realizar ações e tarefas propiciadas pelo jogo: completar missões e aventuras, lutar com monstros e criaturas, enfrentar outros jogadores, conduzir negócios na casa de leilão, participar de atividades e batalhas em grupo, acumular tesouros e recompensas, socialibilizar, etc. 
Figura 1 - Personagem no mundo virtual

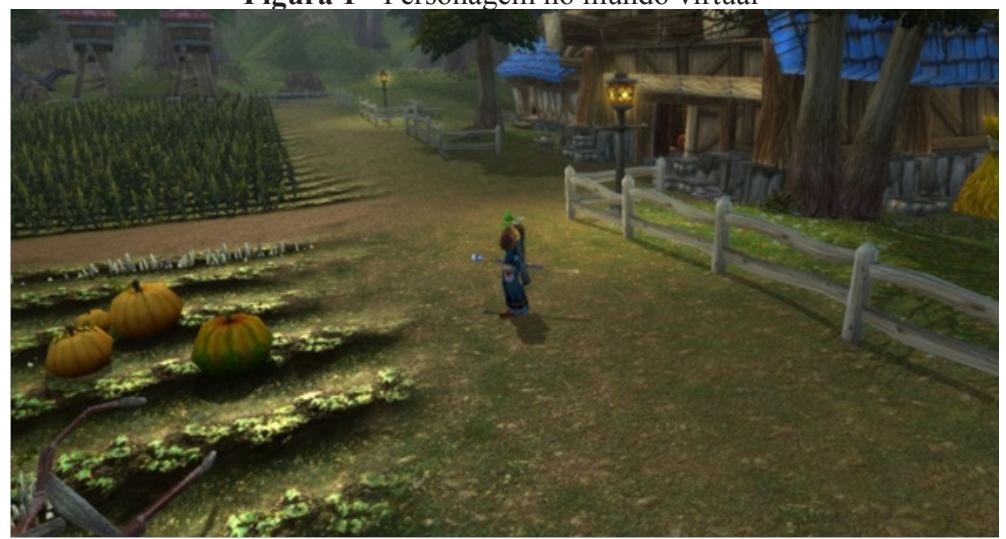

Fonte: printscreen do World of Warcraft. Acervo do autor.

Contrastando com a imagem mostrada na Figura 1, a Figura 2 mostra um cena de ação (luta) em equipe (com outros jogadores) nesse cenário virtual.

Figura 2: A luta: brilhos, luzes e explosões, somados a inúmeras janelas e botões de interface

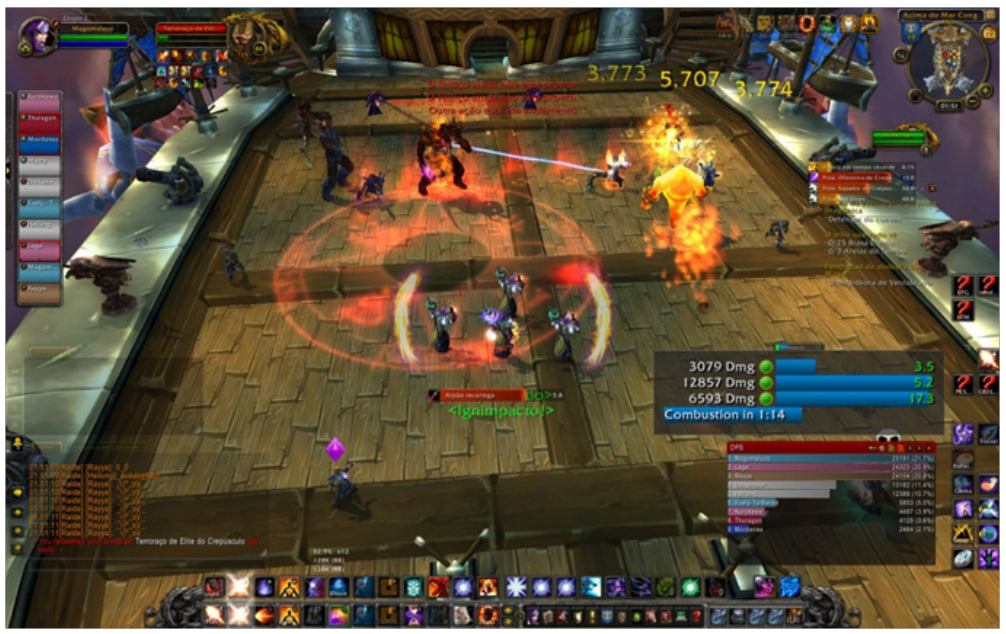

Fonte: printscreen do World of Warcraft. Acervo do autor.

Movimento, Porto Alegre, v. 20, n. 3, p. 1083-1109, jul./set. de 2014. 
Sucesso no crescente universo dos jogos, WoW também pode ser considerado como um importante objeto e campo de estudo em diversas áreas de estudo, especialmente entre aquelas que estabelecem linhas de pesquisa em diálogo com temáticas ligadas à tecnologia, mídia, cibercultura, cultura digital e afins. De trabalhos acadêmicos exclusivamente relacionados ao jogo no cenário internacional (seja como objeto ou campo de estudo), além de diversos artigos publicados em jornais e revistas, tive acesso há pelo menos três livros: "My life as a Night Elf Priest: an anthropological account of World of Warcraft" (NARDI, 2010), produzido a partir da antropologia; "The Warcraft Civilization: social Science in a Virtual World" (BAINBRIDGE, 2010), da sociologia; e a coletânea "Digital Culture, play and identity: a World of Warcraftreader" (CORNELIUSSEN; RETTBERG, 2008), que reuniu pesquisadores de diversas áreas. Já no cenário nacional de pesquisas na pós-graduação, encontrei 11 dissertações de mestrado no Banco de Teses da Capes que possuíam o termo World of Warcraft no resumo ou como palavra-chave. Além desses, outras 14 produções de pós-graduação estavam associadas ao termo mais abrangente, o MMORPG.

Isso mostra que World of Warcraft tem atraído a atenção da comunidade acadêmica e sido considerado relevante como objeto e campo de estudo. A abordagem apresentada ao longo desse trabalho é original na medida em que busca interpretá-lo como prática de lazer, partindo do ponto de vista de jogadores e suas experiências com o jogo.

\section{Metodologia}

Tendo a etnografia como ponto de partida e método estruturante de levantamento e análise dos dados, assumi a condição de jogadorpesquisador e imergi no campo de estudo - o mundo virtual do jogo - acompanhando durante aproximadamente 18 meses as atividades 
quase diárias de jogadores-nativos em seus agrupamentos sociais dentro do jogo - nas chamadas guildas ${ }^{1}$.

Originária dos estudos da antropologia e embora emergente no caso das pesquisas envolvendo o ciberespaço, a etnografia já tem sido usada com frequência em pesquisas na internet e em mundos virtuais, produzindo resultados satisfatórios nesses novos campos de pesquisa, especialmente, como salienta Pearce (2009), quando os objetos de estudo envolvem dinâmicas sociais e construções culturais. Embora tivesse familiaridade com jogos em geral, desconhecia completamente as práticas culturais produzidas e reproduzidas no interior do universo virtual de jogos MMORPG: seria então um estranho aprendendo, assimilando e sendo socializado ${ }^{2}$ na/pela cultura nativa. Nessa dúbia relação, o "transformar o exótico em familiar e vice-versa" (RIFIOTIS, 2010, p. 16) das práticas etnográficas faria pleno sentido.

Tal como na etnografia tradicional, a forma primária de coleta de dados se deu através do trabalho de campo, com a imersão no contexto cultural investigado, o convívio intenso com os nativos e a descrição densa de suas práticas culturais (GEERTZ, 1989).

Nos períodos mais intensos de atividades eu fiquei conectado no jogo de 15 a $25 \mathrm{~h}$ por semana, principalmente à noite - período de maior movimentação no jogo. Durante todo esse período, joguei junto com uma quantidade incontável de jogadores - muitos estrangeiros inclusive - em atividades coletivas nas quais o sistema do jogo agrupava automaticamente jogadores de forma aleatória. A convivência e o relacionamento mais íntimo, no entanto, foram com poucos, restritos à esfera das guildas. O contato social se

\footnotetext{
${ }^{1}$ Guildas são estruturas formais do jogo que possibilitam o agrupamento de jogadores em torno de interesses comuns (objetivos no jogo, laços de amizade, graus de parentesco, etc). As guildas possuem diferentes dinâmicas, a depender dos perfis, preferências, interesses e modos de ser de seus membros. Participar de uma guilda facilita a realização de atividades com outros membros, mas não impede a realização de atividades ou conversas com nãomembros.

${ }^{2}$ A socialização no ciberespaço pode ser entendida como "um conjunto complexo de afinidades, interesses, práticas e discursos que ocorrem como um processo de iniciação no qual interagem experiências online e off-line". (RIFIOTIS, 2010, p. 22)
}

Movimento, Porto Alegre, v. 20, n. 3, p. 1083-1109, jul./set. de 2014. 
estabelecia via canal de bate-papo textual do jogo ${ }^{3}$, softwares de comunicação por voz ${ }^{4}$ e, mais raramente, e-mail.

Como ferramenta acessória à pesquisa de campo, questionários online foram disponibilizados na internet, convidando jogadores a preenchê-lo. Duzentos e cinquenta e um jogadores atenderam ao apelo, respondendo a questões socioeconômicas, de hábitos de lazer e relacionadas com seu envolvimento com o jogo. Também entrevistei formalmente e à distância, via comunicação por voz, outros oito jogadores, com os quais conversei sobre sua vida pessoal, familiar e profissional e também sobre suas preferências com relação a atividades de lazer e suas opiniões sobre o jogar.

As análises das relações sociais produzidas nos ambientes virtuais foram empreendidas com o auxílio de reflexões advindas das ciências sociológicas e antropológicas e de pesquisas sobre jogos do gênero. Entendeu-se que o território do ciberespaço estudado (o mundo virtual de World of Warcraft e seus diversos ambientes virtuais de sociabilidade) podiam ser pensados como uma dimensão constitutiva das sociedades complexas modernas no sentido caracterizada por Velho (1994), sociedades marcadas “por um intenso processo de interação entre segmentos diferenciados e por grande mobilidade material e simbólica", como discute (MAXIMO, 2010, p. 31).

Partiu-se da premissa de que o conjunto de saberes construído acerca das sociedades humanas e suas culturas, especialmente das sociedades complexas, urbanizadas e contemporâneas, são úteis à compreensão das relações sociais produzidas inclusive nas redes e configurações sociais cujas trocas sociais e simbólicas são mediadas por aparatos tecnológicos modernos e efetuadas somente à distância, como no caso dos jogos. Parafraseando a assertiva de Guimarães (2000) observada em seu estudo antropológico no

\footnotetext{
${ }^{3}$ Similar aos canais de conversa encontrados em sítios da internet, como no portal UOL ou chat do Terra.

${ }^{4}$ Softwares como Skype, Ventrillo, TeamSpeaker e RaidCall (esse foi o mais utilizado pelos cores e guildas que participei e por isso é citado mais frequentemente ao longo do texto).
}

Movimento, Porto Alegre, v. 20, n. 3, p. 1083-1109, jul./set. de 2014. 
ambiente virtual criado pela plataforma Palace, não se trata de um estudo do ciberespaço, mas de um estudo no ciberespaço. Em outras palavras, na presente pesquisa o ciberespaço não foi investigado como objeto de estudo carente de uma lente interpretativa exclusivamente construída para sua análise, mas como um espaço social frequentado (mesmo que virtualmente) por indivíduos cujas relações podiam ser interpretadas à luz de teorias e conhecimentos tradicionalmente aplicados aos espaços materialmente constituídos (físicos).

\section{Resultados}

Apresento a seguir algumas das temáticas discutidas no estudo, aqui agrupadas sob os seguintes tópicos: perfis dos jogadores; prática de lazer; performance e competição; sociabilidade; e conflito e violência.

\subsection{Perfis dos SujeItos: diversidade}

Ao público jogador de World of Warcraft, o questionário aplicado aliado a comparações com outras pesquisas e relatos sobre o jogo em específico (NARDI, 2010; CAMPEDELLI, 2009) e jogos similares (SALGADO, 2011; ALVES; HETKOWSKI, 2007), e também a levantamentos sobre a demografia nos universos virtuais dos jogos MMORPGs em geral (YEE, 2006), sugerem a participação de um público que é predominantemente masculino, com idade próxima entre 20 e $30 \operatorname{anos}^{5}$.

Afirmar isso, no entanto, não revela as sutilezas da diversidade e heterogeneidade da atmosfera social e das relações estabelecidas dentro de grupos de jogadores influenciados pela presença de pessoas com idades heterogêneas e de ambos os sexos, destoantes dessa média. A própria observação - participante revelou uma diversidade que o eventual estabelecimento de perfis ou tendências

${ }^{5}$ Média de idade dos 251 respondentes da presente pesquisa em específico: 24,5 variando de 12 até 46 anos.

Movimento, Porto Alegre, v. 20, n. 3, p. 1083-1109, jul./set. de 2014. 
sociais esconderia. A observação em escala individual (através do contato diário com jogadores e da própria entrevista) revelou que os sujeitos, idiossincráticos como tais, são possuidores de estilos de vidas bastante particulares em termos de profissão, escolaridade, relações familiares e hábitos de lazer. Os jogadores entrevistados, por exemplo, todos membros da mesma guilda e parceiros de jogo, certificavam essa diversidade: um pai de duas crianças, de 28 anos, "inspetor de pátio" na escola, cuja diversão se resumia ao WoW; um jovem calouro de direito que trabalha numa floricultura e dizia-se apaixonado por surfe e jiu-jítsu; uma professora, 31 anos, grávida, que jogava junto com o marido; um funcionário público de 28 anos que morava sozinho e cujo lazer estava bastante relacionado à sociabilidade em bares; enfim, uma diversidade de sujeitos possivelmente mascarada numa observação em escala macrossociológica. O quadro abaixo sintetiza elementos de alguns dos entrevistados, expressando essa diversidade. 
Quadro 1 - Resumo geral de 4 jogadores entrevistados

\begin{tabular}{|c|c|c|c|c|c|}
\hline \multirow{6}{*}{ 葋 } & Codnome & Alessandro & Sônia & Marcos & Thiago \\
\hline & Sexo & Masculino & Feminino & Masculino & Masculino \\
\hline & Idade & 28 & 31 & 28 & 19 \\
\hline & Cidade & Interior PR & Goiânia & Brasília & Porto Alegre \\
\hline & Est. Civil & Casado & Casado & Solteiro & Namorando \\
\hline & Mora com & $\begin{array}{l}\text { Esposa grávida }+ \\
\text { menina } 3 \text { anos }\end{array}$ & Marido (está grávida) & Sozinho & $\begin{array}{l}\text { Mãe + irmãos } \\
\text { gêmeos ( } 9 \text { anos) }\end{array}$ \\
\hline \multirow{4}{*}{ 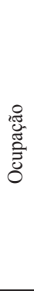 } & Profissão & $\begin{array}{l}\text { Agente Educacional } \\
\text { (inspetor) + monitor } \\
\text { de Xadrez (ensina e } \\
\text { acompanha os alunos }\end{array}$ & $\begin{array}{l}\text { Professora Ens. } \\
\text { Fundamental }\end{array}$ & Funcionário Público & $\begin{array}{l}\text { Estagiário } \\
\text { de Direito }+ \\
\text { floricultura aos } \\
\text { sábados }\end{array}$ \\
\hline & Carga hor. & $40 \mathrm{~h}$ & $38 \mathrm{~h}$ & $30 \mathrm{~h}$ & $20 \mathrm{~h}$ \\
\hline & $\begin{array}{l}\text { Renda } \\
\text { familiar }\end{array}$ & $\begin{array}{l}\text { De R\$ } 927,00 \text { a } \\
1.669,00\end{array}$ & De R\$3.111,00 a $6.220,00$ & $\begin{array}{l}\text { De R\$3.111,00 a } \\
6.220,00\end{array}$ & \\
\hline & $\begin{array}{l}\text { Escolari- } \\
\text { dade }\end{array}$ & $\begin{array}{l}\text { Sup. incompleto } \\
\text { (abandonou } \\
\text { Matemática) }\end{array}$ & $\begin{array}{l}\text { Sup. completo (Biologia) + } \\
\text { Pós (Psicopedagogia) }\end{array}$ & $\begin{array}{l}\text { Iniciou } 6 \text { cursos e } \\
\text { nunca os concluiu }\end{array}$ & $\begin{array}{l}\text { Sup. incompleto } \\
\text { (está no } 1^{\circ} \text { ano } \\
\text { de Direito) }\end{array}$ \\
\hline \multirow[b]{2}{*}{ 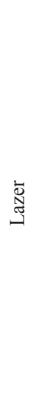 } & $\begin{array}{l}\text { Atividade } \\
\text { fisica, } \\
\text { esportes }\end{array}$ & $\begin{array}{l}\text { As vezes joga futebol } \\
\text { mas admite estar "meio } \\
\text { parado" porque precisa } \\
\text { fazer cirurgia }\end{array}$ & $\begin{array}{l}\text { Iniciou atividades visando } \\
\text { o emagrecimento e } \\
\text { preparação para gravidez, } \\
\text { mas diz que faz "por } \\
\text { obrigação" }\end{array}$ & $\begin{array}{l}\text { Pouco frequentes: } \\
\text { trilhas; tênis de mesa }\end{array}$ & $\begin{array}{l}\text { Pratica Jiujitsu } \\
\text { há } 4 \text { anos; surfa } \\
\text { desde os } 5 \text { anos } \\
\text { (pai dono de } \\
\text { fábrica de surf). } \\
\text { Diz "adorar" } \\
\text { essas práticas }\end{array}$ \\
\hline & Lazer & $\begin{array}{l}\text { "Final de semana e noite } \\
\text { é sempre WoW", relata }\end{array}$ & $\begin{array}{l}\text { Principalmente descansar } \\
\text { nos fins de semana, com } \\
\text { filmes, livros de romance e } \\
\text { visitas a casa de parentes; } \\
\text { admite gostar de práticas } \\
\text { culturais populares, voltadas } \\
\text { aos adolescentes (vê isso } \\
\text { como uma vantagem na sua } \\
\text { profissão) }\end{array}$ & $\begin{array}{l}\text { Bares; Pubs (mais } \\
\text { Rock and Roll); visita } \\
\text { à amigos nos fins de } \\
\text { semana; literatura; } \\
\text { seriados; magás } \\
\text { e animes; Filmes } \\
\text { europeus e antigos; } \\
\text { quebra-cabeças; } \\
\text { eletrônica (hobby: } \\
\text { ex.: montando uma } \\
\text { impressora 3D) }\end{array}$ & \\
\hline \multirow[b]{2}{*}{ 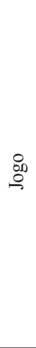 } & $\begin{array}{l}\mathrm{h} / \text { por } \\
\text { semana de } \\
\text { jogo }\end{array}$ & $15 \mathrm{~h}$ & $15 h-25 h$ & $30 \mathrm{~h}$ & \\
\hline & $\begin{array}{l}\text { Contato } \\
\text { presencial } \\
\text { (face a } \\
\text { face)com } \\
\text { amigos } \\
\text { conheci- } \\
\text { dos } \\
\text { através do } \\
\text { jogo }\end{array}$ & $\begin{array}{l}\text { Ele e seus amigos } \\
\text { marcaram encontro em } \\
\text { lan house com pessoas } \\
\text { da cidade vizinha e } \\
\text { foram passar uma } \\
\text { tarde lá. }\end{array}$ & $\begin{array}{l}\text { Seu marido também joga, } \\
\text { já visitaram casais de } \\
\text { jogadores em Brasília (à } \\
\text { passeio) e Belo Horizonte } \\
\text { (missão de trabalho do } \\
\text { marido). Sua principal } \\
\text { motivação no jogo é, } \\
\text { segundo ela, socializar e } \\
\text { fazer amigos. }\end{array}$ & $\begin{array}{l}\text { Diz possuir dois } \\
\text { grandes amigos (de } \\
\text { outros Estados), mas } \\
\text { que "ainda" não os } \\
\text { conhece pessoalmente } \\
\text { por "desleixo" seu; } \\
\text { era inclusive para } \\
\text { terem passado o } \\
\text { último carnaval } \\
\text { juntos; conversam } \\
\text { frequentemente via } \\
\text { Skype. }\end{array}$ & $\begin{array}{l}\text { Já foi junto } \\
\text { com amigos } \\
\text { jogadores para } \\
\text { baladas }\end{array}$ \\
\hline$\tilde{\tilde{o}}$ & Gerais & $\begin{array}{l}\text { Calmo; fala pouco; é o } \\
\text { que mais sofre Bullyng } \\
\text { no jogo (frequentemente } \\
\text { criticado pelos colegas } \\
\text { e motivo de risada); } \\
\text { diz "levar isso na boa", } \\
\text { ficando bravo apenas } \\
\text { consigo mesmo diante } \\
\text { as suas imperícias }\end{array}$ & $\begin{array}{l}\text { Simpática; gosta bastante } \\
\text { do aspecto social do jogo; } \\
\text { tece críticas severas contra } \\
\text { os usos excessivos do jogo; } \\
\text { naõ está jogando mais } \\
\text { como antigamente pois suas } \\
\text { "prioridades" mudaram (em } \\
\text { virtude da gravidez). }\end{array}$ & $\begin{array}{l}\text { Costuma falar de si } \\
\text { e contar histórias; ri } \\
\text { bastante; considera-se } \\
\text { e é tratado como um } \\
\text { iniciante no jogo; } \\
\text { jogou durante muito } \\
\text { tempo sozinho (mas } \\
\text { logado no RC); diz } \\
\text { estar jogando WoW } \\
\text { em substituição do } \\
\text { costume de ir p/bares; }\end{array}$ & $\begin{array}{l}\text { Gosta do } \\
\text { estilo de jogo } \\
\text { competitivo e } \\
\text { performático; } \\
\text { reconhece que } \\
\text { se estressa } \\
\text { facilmente no } \\
\text { jogo e que, por } \\
\text { isso, reclama } \\
\text { bastante. }\end{array}$ \\
\hline
\end{tabular}

Fonte: elaborado pelo autor. 
Além de diversos, percebeu-se nitidamente que tais sujeitos constroem diferentemente para si a experiência do jogar, atribuindo sentidos e significados heterogêneos à prática de forma muito semelhante ao verificado no universo de vivências esportivas e descritos em trabalhos como de Stigger (2002) e Silveira (2008). Ou seja, são sujeitos que estão a jogar juntos, mas não exatamente pelos mesmos motivos e expectativas - diferenças que necessariamente têm que ser negociadas em jogo, mas nem sempre sem tensão. Trabalhos como o do autor evidenciam que entre o esporte profissional e o jogar bola na rua há uma infinidade de maneiras pelas quais os sujeitos manipulam o significado que o esporte tem em suas vidas, bem como o uso que se faz dele. WoW poderia ser pensado na mesma linha.

No caso dos entrevistados apresentados no quadro, cada um justificava sua participação no jogo e dele se apropriava de maneira diferente. Enquanto Sônia dizia jogar quase exclusivamente em função da sociabilidade, da possibilidade de interagir, de se relacionar e de estabelecer laços de amizade com outros jogadores, Thiago parecia estar mais preocupado com sua performance, seu desempenho. Para ele o jogo era uma competição onde poderia se afirmar, ser o melhor, vencer. Devido a esse modo de perceber e se relacionar com o jogo, Thiago priorizou em determinados momentos seu desejo de progressão no jogo e de busca por novos desafios em detrimento da fidelidade ao grupo de amigos e colegas (fidelidade no sentido de constância e não de lealdade). Sônia sem dúvida faria um movimento inverso: deixaria a progressão e a competição de lado para privilegiar atividades sociais e um jogar mais despretensioso e lúdico.

Para o jogador Alessandro, a preocupação com o desempenho e a manutenção da sociabilidade (destacando-se aqui, em especial, o forte vínculo afetivo que possuía com outro jogador) pareciam ser elementos igualmente importantes na construção do sentido de sua participação no jogo. Já no caso de Marcos, o elemento competitivo também parecia estar presente, mas articulado mais a uma ideia de maestria, de aprendizagem para o melhor domínio e

Movimento, Porto Alegre, v. 20, n. 3, p. 1083-1109, jul./set. de 2014. 
menos a uma preocupação performática, voltada para a exibição. Pelos seus comentários, Marcos também parecia valorizar bastante os aspectos estéticos e narrativos do jogo.

\subsection{PRÁtICA DE LAZER}

Constatou-se que em sua maioria World of Warcraft é usufruído como uma prática de lazer doméstica ${ }^{6}$, portanto, inscrito na dinâmica do lar e vinculado aos compromissos a ele relacionados, estando suscetível, por exemplo, ao controle dos pais ou à compulsão social para com membros da família.

Por ser doméstica, é uma prática que ora concorre, ora se alterna, ora se sincroniza com outras atividades realizadas no interior do lar, sejam elas de lazer (internet, televisão, música, conversa, etc.) ou não (família, higiene, necessidades biológicas, etc.). Também por isso, é um tipo de prática de fácil acesso físico: não exige deslocamento, nem gasto de tempo ou recurso com transporte. Essa comodidade e facilidade de acesso possibilita (mas não explica) que o tempo investido na prática (em termos de horas jogadas) seja relativamente alto. De acordo com o questionário aplicado, a média de tempo de uso dos 251 participantes foi de $19,95 \mathrm{~h} /$ semana - valor compatível com os achados de outros estudos envolvendo amostragens significativas, como na pesquisa de Yee (2006), cuja média encontrada para os 30 mil participantes (de vários MMORPGs) foi de $22 \mathrm{~h} /$ semana.

Notou-se que a percepção dos jogadores sobre obrigação, compromisso e necessidade é relativa, gerando formas diferentes de lidar com o WoW em relação às diversas atividades da agenda cotidiana (trabalho, estudo, família, etc). Como já é sabido, o lazer sempre aparecerá articulado a outras dimensões do cotidiano, "estabelecendo relações dialéticas com as necessidades, os deveres e as obrigações, especialmente com o trabalho produtivo" (GOMES, 2004, p. 125). Conscientes ou não, jogadores estão

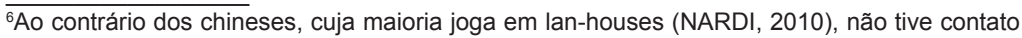
com jogadores que não jogavam World of Warcraft em seus próprios equipamentos.

Movimento, Porto Alegre, v. 20, n. 3, p. 1083-1109, jul./set. de 2014. 
atentos a isso, negociando a todo instante o aproveitamento do seu tempo com maior ou menor conflito a depender de seu maior ou menor interesse com o jogo e da rigidez ou maleabilidade de suas obrigações.

\subsection{Performance e COMPetıÇÃo}

Embora ofereça a seus jogadores um leque variado de atividades para se divertirem, a maioria das atividades realizadas do jogoestá embebida em um princípio orientador comum: a performance. Fala-se aqui da busca de desempenho, da atuação visando melhor resultado, sobretudo em público (na presença mesmo que virtual de outros jogadores). A performance, realizada de diferentes maneiras e materializada sob diversas formas no jogo, principalmente na demonstração de superioridade através de conhecimento (saber) e habilidade (saber fazer) e no acúmulo de bens simbólicos e materiais (títulos, itens, tesouros, etc.), é o elemento central do jogo, tornado possível somente pela natureza social dele.

Social porque o jogo não é construído ou posto em funcionamento como nos jogos digitais tradicionais, somente pela sua estrutura, arquitetura e mecânica - previamente determinadas pelos desenvolvedores - mas sim pela inter-relação dessas com uma complexa e fortemente arraigada dinâmica social, a qual regula, orienta, molda e determina maneiras de jogar e formas de agir e se comportar no jogo, e que não é formada senão pela relação interdependente dos jogadores uns com os outros no contexto do jogar - fato que passa um tanto despercebido pela maioria das pesquisas do gênero ${ }^{7}$.

Outro ponto a destacar é que a competição exacerbada, somada a complexidade e dificuldade próprias de certas atividades coletivas (realizadas em grupos tais quais equipes esportivas) nem sempre são vivenciadas tão harmonicamente como a análise

${ }^{7}$ A principal exceção seria a pesquisa de Chagas (2010).

Movimento, Porto Alegre, v. 20, n. 3, p. 1083-1109, jul./set. de 2014. 
de Nardi (2010) e outros pesquisadores fazem parecer. São, pois, nem sempre "[...] geradoras de um incrível nível de amabilidade e positiva sociabilidade [...]" ou desenhadas "[...] para encorajar bondade e cordialidade entre os pares [...]" (NARDI, 2010, p. 120) ${ }^{8}$, como enxergou a pesquisadora. Por vezes, resultam na explosão de emoções e sentimentos que terminam em episódios de elevada tensão e conflito. Protegidos pela distância temporal e profundamente excitados pelo calor do jogo, não é de todo raro presenciar jogadores interagindo de forma agressiva e simbolicamente violenta ${ }^{9}$ (trocas de ofensas verbais nas comunicações por voz ou através dos canais do bate-papo; expulsões de jogadores).

Diversas vezes presenciei situações nas quais, embora não tivessem chegado a ser expulsos das equipes (o que é muito frequente), os jogadores tiveram sua performance negativamente avaliada, acompanhada de comentários mais ácidos e até mesmo xingamentos. Comum nesses casos é o jogador criticado ser chamado pejorativamente de noob. Diferente de ser chamado de "perna-de-pau" no futebol, por exemplo, onde a expressão denota incapacidade ou incompetência motora, um falta de habilidade de natureza "física", ser chamado de noob pode ser sentido como uma ofensa mais severa, já que a falta de habilidade no jogo não é interpretada como resultado de uma dificuldade motora, mas intelectual: uma incapacidade de pesquisar e entender melhor o jogo, de conhecer os "detalhes, as manhas"; de saber o que fazer em cada situação. Assim, no contexto de avaliação da performance, ser chamado de noob pode significar perfeitamente ser chamado de ignorante, mentalmente incapaz ou idiota. $\mathrm{Vi}$, por exemplo, jogadores anunciarem vagas para suas equipes com exigências do tipo "tem que ter cérebro".

\footnotetext{
${ }^{8}$ Tradução livre do original: "generative of an amazing level of amiability and positive sociability [e] designed to encourage bonhomie and cordiality among peers".

${ }^{9}$ Violência simbólica entendida como aquela que opera por meio de símbolos, destacadamente a linguagem, e que pode ferir o indivíduo não fisicamente ou corporalmente, mas sua consciência, autoestima, moral, reputação ou prestígio (cf. ELIAS, 1993; ZALUAR; LEAL, 2001).
}

Movimento, Porto Alegre, v. 20, n. 3, p. 1083-1109, jul./set. de 2014. 
Nas atividades coletivas, a utilização pelos jogadores de aplicativos acessórios que monitoram o desempenho dos membros da equipe e fornecema todo momento dados quantitativos acerca das ações de cada jogador (equivalente aos scouts no âmbito esportivo) permite a completa racionalização da performance e instaura estados de permanente vigilância: o erro é facilmente identificado e comprovado.

Em função da dinâmica estabelecida - a dificuldade e complexidade do jogo, a vigilância constante, a pressão do grupo, a fatalidade do erro, a acirrada competitividade, a primazia pela performance e sua racionalização e quantificação, a mistura de jogadores desconhecidos (inclusive de distintas nacionalidades) com acentuadas diferenças nos níveis de habilidade - a prática de certas atividades no WoW pode ser deveras tensa e excitante (ELIAS; DUNNING, 1992); propícia, portanto, ao extravasamento das emoções, desde a alegria delirante da conquista de uma vitória após dias ou semanas de tentativas frustradas, até a raiva profunda com o colega que não atua corretamente ou que cobra e exige insistente e impacientemente uma atuação correta. Também, por todos esses motivos, nem sempre é divertida, prazerosa: jogadores podem sair particularmente incomodados e entristecidos por conta do seu próprio desempenho (precisamente, da avaliação pública do seu desempenho) ou por conta do desempenho de outrem, que, sendo insuficiente, impede seu desejado sucesso.

\subsection{SOCIABILIDADE}

Quanto à sociabilidade - o prazer do estar junto e do conviver amigavelmente com o outro como um fim último (SIMMEL, 1983) - há que se destacar que, embora constantemente referida como a pedra fundamental dos jogos MMORPGs ${ }^{10}$, sua presença é dúbia, ao menos no $W o W$. Por uma perspectiva, o universo virtual

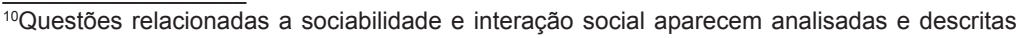
em diversos trabalhos a respeito desse gênero de jogos, como em Alves Silva (2010), Andrade (2007), Campedeli (2009), Falcão (2010), Ibargoyen (2011), Salgado (2011), Sepe (2007), para citar pesquisas de pós-graduação nacionais.
}

Movimento, Porto Alegre, v. 20, n. 3, p. 1083-1109, jul./set. de 2014. 
do jogo certamente se configura como espaço social propício ao estabelecimento de interações sociais pontuais cuja recorrência no tempo fatalmente leva à construção ou consolidação de laços sociais afetivos eventualmente intensos e duradouros. A possibilidade de "fazer amigos" e "conhecer pessoas", amplamente citada nos questionários e fóruns e frequentemente observada na pesquisa de campo, pode ser considerada impactante na esfera do jogo. Houve aqueles que assumiram só continuar jogando por causa das amizades constituídas dentro do jogo, e outros que relataram ter inclusive viajado e se deslocado para conhecer pessoalmente, face -a -face, os novos amigos. Se para alguns o WoW representava um espaço social distante da realidade cotidiana, mas ainda assim um lugar onde se poderia, tal como qualquer outro, conhecer pessoas e fazer amigos, para outros ele representava uma espécie de extensão dos espaços sociais cotidianos, isto é, mais um lugar de lazer para onde se iria com amigos, conhecidos e familiares se divertir.

Notou-se também que jogar sozinho não pode ser tomado como parâmetro de interação e relacionamento social visto que, para aqueles cuja sociabilidade é valorizada, parte considerável do jogar pode acontecer no formato sozinho, mas junto: sozinho na atividade em si e distante geograficamente no ambiente virtual, mas junto com os colegas e amigos via comunicação por voz ou escrita. Em todos esses casos, a sociabilidade certamente figura como elemento importante - decisivo, para alguns - na experiência do jogar.

Por outra perspectiva, observamos uma situação inversa, mas também corriqueira no jogo: o jogar junto, mas sozinho. Muitos jogadores que não fazem questão de sociabilizar, de conhecer outros jogadores, de conversar e "bater -papo" no jogo, mas também inclusive aqueles que prezam a sociabilidade in-game, se reúnem em atividades aleatórias com finalidades puramente associativas, sem qualquer outra finalidade senão o simples e puro cumprimento destas. Aliás, o fazem da maneira mais pragmática, rápida e objetiva possível; um jogar que faz do outro e da própria atividade em si apenas um meio para consumação de uma meta: a

Movimento, Porto Alegre, v. 20, n. 3, p. 1083-1109, jul./set. de 2014. 
obtenção de itens, conquistas, pontos e demais bens e patrimônios embutidos no sistema de recompensas do jogo. Daí, portanto, a noção de estar jogando junto com outros jogadores, mas ao mesmo tempo com a sensação de estar só, com sentimento de solidão, visto que a relação de dependência entre os jogadores é praticamente nula, tanto que pode ser quebrada a qualquer instante e o jogador imediatamente substituído (pelo próprio sistema do jogo que se encarrega de agrupar automaticamente os jogadores). Não se pode contar com o outro, carecer de sua ajuda, nem se pode dele depender ou nele confiar, afinal, estão somente "pegando a mesma ponte aérea" - para emprestar a citação de um jogador - naquela dada atividade e nunca mais vão se encontrar.

\subsection{Conflito E VIOLÊNCIA SIMBÓLICA}

Importante ressaltar que, na condição de juntos, mas sozinhos, apesar dos jogadores não estarem sociabilizando, conversando amistosamente e interagindo ativamente uns com os outros, não significa que estejam livres de influências sociais dos demais. Pode não haver conversa, diálogo ou acordos explícitos, mas o jogador sabe que existem jogadores do outro lado esperando que ele aja de certa maneira; sabe que a não correspondência das expectativas dos demais ou que o agir displicente pode instituir estados de tensão, conflito e violência que podem inclusive culminar na sua total rejeição: ser kickado (expulso) do grupo.

Há modos de jogar socialmente aceitos e outros não. Em sua trajetória e constituição enquanto sujeito-jogador, o indivíduo sofrerá sucessivos processos de socialização (RIFIOTIS, 2010) a partir de valores, etiquetas, normas de conduta, padrões de autocontrole, maneiras corretas de jogar, que moldarão mais ou menos acentuadamente sua participação no jogo, a qual, por extensão, repercutirá e reforçará o processo de socialização e conformação do jogar dos novos jogadores, iniciantes. Antes que se perceba, todos estão jogando de maneira mais ou menos igual, valorizando mais ou menos as mesmas coisas, sem que se faça qualquer acordo explícito a respeito.

Movimento, Porto Alegre, v. 20, n. 3, p. 1083-1109, jul./set. de 2014. 
A análise nos faz afirmar que WoW é um jogo essencialmente social, independente de favorecer ou não a sociabilidade - o relacionamento social, a comunicação com o outro como um fim em si mesmo (SIMMEL, 1983) - e o fato de ser social tem implicações profundas na forma como as diversas experiências de jogar se organizam. Jogadores em suas relações uns com os outros e em constante negociação com as limitações/determinações do software (a mecânica, o design, a estrutura que vêm de fábrica) estabelecem e orientam de maneira não planejada a forma como o jogo deve ser jogado.

Outro ponto a se destacar é que no universo virtual do jogo as relações estabelecidas não são necessariamente harmônicas e nem sempre a interação se dá de forma amistosa, cordial ou pacífica.

A presença de jogadores - distantes fisicamente mas virtualizada através de seus avatares - institui relações de poder (ELIAS, 1999) decorrente dos desafios do jogar. Quanto mais difícil a atividade e quanto mais desconhecidos entre si forem os membros do grupo, maior pode ser a tensão existente. E quanto mais experiente, mais habilidoso, mais conhecedor do jogo, mais da elite for o jogador e mais equipado e competitivo for seu personagem, mais a balança de poder pende para seu lado. Mais autoridade ele terá para negociar ou impor sua vontade ou opinião aos demais, especialmente em relação aos menos habilidosos, mais inexperientes, novatos, noobs. E onde há relações de poder, isto é, em toda e qualquer configuração social (ELIAS, 1993), sempre há possibilidades de que com o desgaste das relações, com a colisão de interesses e com as disputas por privilégios, reconhecimento e prestígio, se instaurem esporádica ou permanentemente estados sociais de relativo desconforto, frustração e crise, eventualmente descambando para situações de intenso conflito e até mesmo violência simbólica. Inevitáveis rupturas e rearranjos nas teias sociais tornam-se inevitáveis.

De fato, comportamentos intolerantes, agressivos e violentos puderam ser testemunhados em diversos episódios no jogo e 
confirmados por inúmeros relatos e manifestações de jogadores nos fóruns e questionário. $\mathrm{O}$ episódio descrito a seguir, exemplifica como a tensão-excitação pode descambar para uma situação de intolerância e violência simbólica.

Era um grupo de 25 jogadores. Com a exceção de poucos jogadores - uns sete ou oito que compunham o núcleo principal e que estavam organizando a atividade (eles vinham da mesma guilda) - os demais vinham de guildas distintas e, por isso, não se conheciam. O grupo todo já estava reunido e jogando continuamente havia quase três horas. Muitos já estavam cansados, exaustos, e os organizadores da atividade um tanto impacientes. Após mais três tentativas bastante desorganizadas de realização da atividade, ambas resultantes em derrota (morte de todos os personagens), e vendo que a quarta também estava indo por água abaixo, jogadores do núcleo principal (conhecidos entre si) perderam a paciência e se exaltaram (através do sistema de voz):

Jogador1, indignado:

- Ahh... eles são muito burro! [se referindo a outros jogadores do grupo que não estavam agindo adequadamente, sem citar nomes, sem dizer exatamente quem].

- Cara, na boa, como o ser humano consegue ser tão otário assim. [alguém ri ao fundo].

- Eu não entendo como a gente é a porra da raça dominante. Cara, na boa. [nenhum dos criticados responde]

Jogador2, dando instruções necessárias à atividade, porém num tom de deboche:

- Leva tudo esses adds [monstros] lá pra perto do boss [chefe] e pode matar.

- Leva tudo, galera! Leva tudo!

E acentua o tom de deboche, insinuando que todos já deveriam saber o que fazer:

- É, é, é tão fácil.

Movimento, Porto Alegre, v. 20, n. 3, p. 1083-1109, jul./set. de 2014. 
- Ó, por exemplo: se tá perto do tank, vai lá! Dá AoE! [a instrução é pronunciada num tom bastante debochado. Ao fundo, escuta-se uma risada feminina].

- É fácil. É coisa de pegar na mão. É coisa de pegar na mão do cara e fazer assim:

[muda para um tom de voz paternal, como se estivesse ensinando o próprio filho]

- Não... Tá errado meu filho... Não é desse jeito. Vêm aqui ó.

Jogador1 complementa:

- Pegar na mão, não! Tem que matar uma porra dessa!

Não houve respostas às provocações. O exemplo mostra a indignação de alguns jogadores frente à atuação de outros no grupo. Mesmo sem direcionar a crítica e apontar quem eram os responsáveis pelo fracasso, é possível ao jogador atento perceber se as críticas são dirigidas ou não a ele.

As análises e interpretações realizadas ao longo do estudo indicaram condições que parecem ser propícias à eclosão de tais episódios:

a) Heterogeneidade de sentidos e significados atribuídos à mesma atividade e, a isso associado, a dificuldade de negociação desses diferentes sentidos enquanto o jogar se desenrola;

b) Hegemonia da dinâmica performática e competitiva no jogar, ou seja, a prevalência do jogar em busca de resultado (itens, reputação, etc.);

c) Racionalização e quantificação da performance, possibilitando a avaliação recíproca e comparação de desempenho através de dados quantitativos (scouts), captados e sistematizados poraplicativosacessórios ao jogo, instaurando estados de intensa e constante vigilância;

Movimento, Porto Alegre, v. 20, n. 3, p. 1083-1109, jul./set. de 2014. 
d) Amplitude e discrepância nos níveis de conhecimento e habilidade dos membros de um mesmo grupo;

e) Presença volátil e efêmera de jogadores anônimos, desconhecidos entre si, mas agrupados automaticamente e a todo instante pelo jogo;

f) Relativa frouxidão nos padrões de autocontrole e regulação da conduta propiciados pela presença ineficaz ou sensação de ausência de monopólio da violência simbólica e de mecanismos de controle efetivos do seu exercício no mundo virtual do jogo;

\section{Considerações Finais}

A pesquisa revelou que WoW é uma prática de lazer essencialmente doméstica e que, se por um lado reúne,como em outros MMORPGs, jogadores principalmente do sexo masculino, de 20 a 30 anos de idade,por outro, atrai sujeitos que, quando olhados singularmente, apresentam perfis socioeconômicos e de hábitos de lazer bastante variados, imprimindo certa heterogeneidade nos grupos (guildas). O desfrute do jogo como atividade de lazer se dá de maneira bastante diversa: tais como nas atividades esportivas jogadores de WoW atribuem diferentes sentidos e significados a sua prática.

Para além da sociabilidade (característica sem dúvida importante), o aspecto social do jogo é absolutamente determinante da experiência do jogar, presente na hierarquização dos resultados, na exibição pública das performances e das conquistas, na valorização das recompensas e formas de jogar e, logicamente, na maneira de agir e se comportar online; social este construído pelo entrelaçar dinâmico das experiências de jogar e se relacionar de cada um dos jogadores.

Concluo afirmando que, ao contrário do que geralmente costuma ser observado e enfatizado acerca da suposta violência presentes nos jogos digitais e usado para descrevê-los como violento

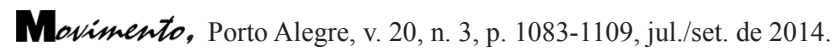


ou como incitador de comportamentos violentos (SETZER, 2001), em se tratando do WoW e possivelmente de outros jogos do gênero, o principal tipo de violência a que os jogadores estão sujeitos no jogar não é a que reside no aspecto bélico do jogo, nas representações gráficas das armas, dos monstros, das lutas ou das mortes, mas fundamentalmente na relação social estabelecida entre os jogadores.

Nesse sentido, seria importante refletirmos e verificarmos se, no cotidiano das atividades esportivas onde participam grupos compostos por sujeitos que não compartilham de mesmos sentidos e significados atribuídos à prática, especialmente em situações de competição exacerbada ou quando envolvem registros quantitativos da performance, eventualmente episódios de violência simbólica não estão, dissimuladamente, maculando relações e o próprio fazer pedagógico. 


World of warcraft as leisure: sociability and conflict in
cyberspace.
Abstract: World of Warcraft is a very well-known digital game
that is played worldwide. In the virtual world of the game,
thousands of people connected to the internet come together
to interact, relate and share the experience of playing. This text
is a summary of the main findings of ethnographic research that
addressed the game as a leisure practice and from players'
perspective. The main topics discussed include issues related to
performance, competition, sociability and violence.
Keywords: Games; Leisure; Sociability; Violence.

World of warcraft como práctica de ocio: sociabilidad y
conflicto "en juego" en el ciberespacio.
Resumen: World of Warcraft es un juego digital y muy bien
conocido y jugado en todo el mundo. En el mundo virtual de
juego, miles de personas conectadas a internet se reúnen para
interactuar, relacionarse y compartir la experiencia de jugar.
Este texto es un resumen de las principales conclusiones de
la investigación etnográfica que abordaron el juego como una
práctica de ocio y desde la perspectiva de los jugadores. Entre
los principales temas tratados están las cuestiones relacionadas
con el rendimiento, la competencia, la sociabilidad y la violencia.
Palabras clave: juegos digitales; ocio; sociabilidad; violencia.

\section{REFERÊNCIAS}

ALVES, L.; HETKOWSKI, T. M. Gamersbrasileiros: quem são e como jogam? In: DESENVOLVIMENTO Sustentável e Tecnologias da Informação e Comunicação. Salvador: Edufba, 2007. p. 161-174. Disponível em: <http://www.lynn.pro.br/admin/ files/lyn_artigo/4f676f0918.pdf>. Acesso em: jul. 2013.

ALVES SILVA, R. P. World of Warcraft: semioses para produção de envolvimento em jogos eletrônicos. Dissertação (Mestrado em Comunicação Social) Universidade Federal de Juiz de Fora, Juiz de Fora, 2010.

ANDRADE, L A. A Galáxia de Lucas: sociabilidade e narrativa nos jogos eletrônicos. Dissertação (Mestrado em Comunicação) - Universidade Federal Fluminense, Niterói, 2007.

ARAUJO, B. M. R. de et al. Virtualização esportiva e os novos paradigmas para o movimento humano. Motriz, Rio Claro, v. 17, n. 4, dez. 2011.

CAMPEDELLI, G. Bem-vindos a Azeroth: aspectos da economia lúdica nos mundos fantásticos. Dissertação (Mestrado em Comunicação) - Escola de Comunicações e Artes, Universidade de São Paulo, São Paulo, 2009. 
World of warcraft como prática de lazer ...

BAINBRIDGE, W. S. The Warcraft Civilization: social science in a virtual world. Cambridge: The MIT, 2010.

BARACHO, A. F. O; GRIPP, F. J; LIMA, M. R. Os exergames e a educação física escolar na cultura digital. Revista Brasileira de Ciências do Esporte, Florianópolis, v. 34, n. 1, p. 111-126, jan./mar. 2012.

CHAGAS, A. O. O transbordamento do lúdico e a biopolítica em jogos MassiveMultiplayer online: um estudo sobre World of Warcraft. 2010. 153 p. Dissertação (Mestrado em Educação) - Faculdade de Educação, Universidade de São Paulo, São Paulo, 2010.

CORNEliUsSEN, H. G.; RETTBERG, J. W. (Org.). Digital Culture, Play and Identity: A World of Warcraft Reader. Cambridge: The MIT, 2008.

COSTA, A. Q. Mídias e jogos: do virtual para uma experiência corporal educativa. Dissertação (Mestrado em Ciências da Motricidade Humana) - Universidade Estadual Paulista Júlio de Mesquita Filho, São Paulo, 2006.

CRUZ JUNIOR, G.; SILVA, E. M. A (ciber)cultura corporal no contexto da rede: uma leitura sobre os jogos eletrônicos do século XXI. Revista Brasileira de Ciências do Esporte, Porto Alegre, v. 32, n. 2-4, p. 89-104, dez. 2010.

ELIAS, N. O processo civilizador. Tradução de Ruy Jungman. Rio de Janeiro: Zahar, 1993. v. 2. 307 p.

ELIAS, N. Introdução à sociologia. Tradução de Maria Luísa Ribeiro Ferreira. Lisboa: Edições 70, 1999. 202 p.

ELIAS, N.; DUNNING, E. A busca da excitação: desporto e lazer no processo civilizacional. Tradução de Maria Manuela Almeida e Silva. Lisboa: Difel, 1992.

FALCAO, T. P. Uma incursão sobre as estruturas comunicacionais em mundos virtuais: estudo sobre a mediação dos diálogos pela figura do jogo. $186 \mathrm{p}$. Dissertação (Mestrado em Comunicação e Cultura Contemporânea) - Universidade Federal da Bahia, Salvador, 2010.

FERES NETO, A. A virtualização do esporte e suas novas vivências eletrônicas. 117 f. Tese (Doutorado em Educação) - Faculdade de Educação, Universidade Estadual de Campinas, Campinas, 2001.

GEERTZ, C. A Interpretação das Culturas. Rio de Janeiro: RTC, 1989.

GOMES, C. L. Lazer - Concepções. In: GOMES, C. L. (Org.). Dicionário Crítico do Lazer. Belo Horizonte: Autêntica, 2004. p. 119-126.

GUIMARAES, M. J. L. Vivendo no Palace: etnografia de um ambiente de sociabilidade no Ciberespaço. Dissertação (Mestrado em Antropologia) - Universidade Federal de Santa Catarina, Florianópolis, 2000.

IBARGOYEN, D. D. Jogos virtuais e a antropologia da performance. Dissertação (Mestrado em Ciências Sociais) - Universidade Estadual de Maringá, Maringá, 2011.

Movimento, Porto Alegre, v. 20, n. 3, p. 1083-1109, jul./set. de 2014. 
MAXIMO, M. E. Da metrópole às redes sociotécnicas: a caminho de uma antropologia no ciberespaço. In: RIFIOTIS, T.; MAXIMO, M. E.; LACERDA, J.; SEGATA, J. (Org.). Antropologia no Ciberespaço. Florianópolis: Editora da UFSC, 2010. p. 17-27.

NARDI, B. A. My life as a night elf priest: an anthropological account of world of warcraft. Michigan, The University of Michigan Press, 2010.

PEARCE, C. Communities of Play: emergente cultures in multiplayer games and virtual worlds. Cambridge: The MIT, 2009.

PENG, W; CROUSE, J. C.; LIN, J. H. Using active video games for physical activity promotion: a systematic review of the current state of research. Health Education and Behavior, Columbia, v. 40, n.2, p. 171-192, Apr. 2013.

PEREIRA, R. S. Avatares no Second Life: corpo e movimento na constituição da noção de pessoa on-line. Dissertação (Mestrado em Educação Física) Universidade Federal de Santa Catarina, Florianópolis, 2009.

REIS, L. J. A. Sozinho mas junto: sociabilidade e violência no World of Warcraft. Tese (Doutorado em Educação Física) - Universidade Federal do Paraná, Curitiba, 2013.

RIFIOTIS, T. Antropologia do Ciberespaço: questões teórico-metodológicas sobre pesquisa de campo e modelos de sociabilidade. In: RIFIOTIS, T.; MAXIMO, M. E.; LACERDA, J.; SEGATA, J. (Org.). Antropologia no Ciberespaço. Florianópolis: Editora da UFSC, 2010. p. 17-27.

SALGADO, M. M. Sociabilidade em espaços digitais complexos de MMORPG. Dissertação (Mestrado em Comunicação na Contemporaneidade) - Faculdade Cásper Líbero, São Paulo, 2011.

SEPE, C. P. Navegando na rede de interações de um RPG Online: um estudo de caso do game Erínia. Tese (Doutorado em Comunicação) - Universidade do Vale do Rio dos Sinos, São Leopoldo, 2007.

SETZER, V. W. Meios eletrônicos e educação: uma visão alternativa. São Paulo: Escrituras, 2001.

SILVEIRA, R. Esporte, homossexualidade e amizade: estudo etnográfico sobre o associativismo no futsal feminino. Dissertação (Mestrado em Ciências do Movimento Humano) - Universidade Federal do Rio Grande do Sul, Porto Alegre, 2008.

SIMMEL, G. Individualidade, interação, tipo social. In: MORAES FILHO, E. (Org.). Sociologia. São Paulo: Ática, 1983.

STIGGER, M. P. Esporte, lazer e estilos de vida. Campinas: Autores Associados, 2002.

VELHO, G. Projeto e metamorfose. Rio de Janeiro: Jorge Zahar, 1994.

Movimento, Porto Alegre, v. 20, n. 3, p. 1083-1109, jul./set. de 2014. 
World of warcraft como prática de lazer ...

YEE, N. The Daedalus Project. 2006. Disponível em: http://www.nickyee.com/ daedalus/archives/001524.php. Acesso em 10/03/2012.

ZALUAR, A.; LEAL, M. C. Violência extra e intramuros. Revista Brasileira de Ciências Sociais, São Paulo, v. 16, n. 45, p.145-164. fev. 2001.

Endereço para Correspondência

Universidade Federal do Paraná

Programa de Pós-graduação em Educação Física

Departamento de Educação Física

Rua Coração de Maria, 92

Campus Jardim Botânico - CEP 80210-132 - Curitiba/Paraná

Recebido em: 04.11.2013

Aprovado em: 14.05.2014

Movimento, Porto Alegre, v. 20, n. 3, p. 1083-1109, jul./set. de 2014. 